\title{
PENGENDALIAN BAHAN BAKU BATU SILIKA PADA PT. SEMEN PADANG
}

\author{
Henny Yulius ${ }^{1}$, Yudi Saputra Mardani ${ }^{2}$ \\ ${ }^{1}$ Jurusan Teknik Industri, Sekolah Tinggi Teknologi Industri Padang \\ email: henny.yulius0101@gmail.com
}

\begin{abstract}
Abstrak: Pengendalian persediaan merupakan salah satu yang sangat penting bagi perusahaan, karena tanpa pengendalian persediaan yang tepat perusahaan akan mengalami masalah dalam memenuhi kebutuhan konsumen baik dalam bentuk barang maupun jasa yang dihasilkan oleh perusahaan tersebut. PT. Semen Padang memiliki jumlah persediaan yang tersedia dalam kondisi berlebih, dimana mengakibatkan perusahaan mengalami pemborosan persediaan. Saat ini persediaan yang dikeluarkan oleh perusahaan masih tergolong besar yaitu rata - rata sebanyak 76.465 ton/bulanya. Tujuan penelitian ini untuk mengetahui apakah penerapan metode Material Requipment Planning (MRP) dapat merencanakan persediaan bahan baku batu silika telah optimal. Metode yamg diterapkan dalam penelitian ini adalah metode Material Requipment Planning dengan teknik Economic Order Quantity. Hasil yang didapatkan adalah Material Requirement Planning (MRP) dengan metode EOQ biaya yang lebih optimal.
\end{abstract}

Kata kunci : Persediaan, Material Requirement Planning (MRP), Economic Order Quantity (EOQ)

Abstract: Inventory control is a very important one for the company, because without proper inventory control the company will have problems in meeting the needs of consumers both in the form of goods and services produced by the company. PT. Semen Padang has an excess amount of inventory available, which results in the company experiencing a waste of inventory. At present the inventory released by the company is still relatively large, with an average of 76,465 tons / month. The purpose of this study was to determine whether the application of the Material Requipment Planning (MRP) method could plan the inventory of silica stone raw materials was optimal. The method applied in this research is Material Requipment Planning method with Economic Order Quantity technique. The results obtained are Material Requirement Planning (MRP) with a more optimal cost EOQ method.

Keywords: Keywords: Inventory, Material Requirement Planning (MRP), Economic Order Quantity $(E O Q)$

\section{PENDAHULUAN}

Pengendalian persediaan yang merupakan salah satu asset penting dalam perusahaan perlu mendapat perhatian khusus dari manajemen perusahaan. Hal tersebut dilakukan bertujuan agar dapat melayani kebutuhan produksi dengan tepat dan biaya yang rendah. Pada umumnya perusahaan melakukan pengendalian tidak berdasarkan metode-metode yang sudah baku, tetapi hanya berdasarkan pada pengalaman-pengalaman sebelumnya. Hal tersebut tentu sering mengakibatkan

terjadinya kelebihan bahan baku ataupun kekurangan bahan baku yang menyebabkan keterlambatan produksi dan pembengkakan biaya, dan tentunya akan terjadi keterlambatan dalam memenuhi kebutuhan konsumen. Berangkat dari pentingnya pengendalian bahan baku tersebut, salah satu permasalahan persediaan yang terjadi pada perusahaan manufaktur khususnya pada PT. Semen Padang yaitu jumlah persediaan yang tersedia dalam jumlah yang terlalu besar atau persediaan dalam kondisi berlebih mengakibatkan perusahaan mengalami 
pemborosan persediaan yang menyebabkan persediaan yang dikeluarkan oleh perusahaan, saat ini masih tergolong besar yaitu rata - rata sebanyak 76.465 ton/bulanya. Namun jika persediaan tersedia dalam jumlah yang terlalu kecil atau persediaan di bawah kondisi minimum, perusahaan akan mengalami kesulitan dalam memenuhi permintaan.

Batasan masalah dalam penelitian ini adalah sebagai berikut: Penelitian ini dilakukan hanya dalam ruang lingkup biro perencanaan dan evaluasi produksi PT Semen Padang. Peneliti hanya meneliti data tentang persediaan batu silika tahun 2019. Metode yang di pakai dalam penelitian ini yaitu metode material requirement planning (MRP).

\section{METODE PENELITIAN}

Metodologi penelitian menjelaskan mengenai langkah-langkah yang dilakukan dalam penyelesaian masalah.

Studi pendahuluan dilakukan dengan tujuan untuk mengamati objek yang akan diteliti dan mengetahui rumusan masalah dari objek yang diamati. Dalam proses produksi, suatu perusahaan dituntut untuk menghasilkan suatu produk berkualitas yang sesuai dengan keinginan konsumen. Lancar atau tidaknya proses produksi suatu perusahaan ditentukan oleh persediaan bahan baku. Ketika persediaan bahan baku melebihi kebutuhan perusahaan maka hal ini dapat menyebabkan penambahan biaya pemeliharaan dan biaya penyimpanan, terlebih resiko yang akan ditanggung apabila bahan baku yang disimpan menjadi rusak atau tidak layak pakai. Sebaliknya, bila perusahaan berupaya mengurangi persediaan, maka perusahaan akan dihadapkan pada kekurangan persediaan sehingga akan mengganggu kelancaran proses produksi perusahaan.Tahapan ini merupakan studi lebih lanjut dengan cara mencari referensi-referensi yang relevan dengan masalah yang akan diteliti. Hal ini bertujuan agar penelitian memiliki landasan yang kuat. Pada tahap ini dilakukan pengumpulan referensi-referensi yang berkaitan dengan permasalahan yang berhubungan dengan peramalan dan metode Material Requirement Planning (MRP). Ada beberapa metode peramalan kuanlitatif, yang hampir seluruhnya menggunakan data historis atau deret waktu (time series). Berikut adalah metode peramalan kuantitatif dirincikan sebagai berikut (Assauri, 2016) :

\section{Metode Linear}

Salah satu teknik prakiraan ramalan adalah Linear dari suatu deret waktu. Analisis tren merupakan cakupan pengembangan suatu persamaan yang cocok untuk menggambarkan tren, dengan asumsi, bahwa dalam data terdapat yang sekarang, Komponen data deret waktu dalam tren, mungkin linear ataumungkin tidak linear.

Dengan perkiraan tren bentuk persamaan yang digunakan adalah sebagai berikut

$$
\mathrm{F}_{\mathrm{t}}=\mathrm{a}+\mathrm{bt}
$$

Keterangan:

$\mathrm{F}_{\mathrm{t}}=$ Ramalan untuk periode $\mathrm{t}$

$\mathrm{a}=$ Nilai dari $\mathrm{F}$ pada saat $\mathrm{t}=0$

$\mathrm{b}=$ slope dari garis, dimana slope adalah tingkat kemiringan.

$\mathrm{t}=$ jumlah tertentu dari periode waktu, mulai dari $\mathrm{t}=0$

Pehitungan peramalan dari tren linear, dapat dilakukan dengan dua persamaan yaitu :

$$
\begin{aligned}
& b=\frac{n \sum t y-\sum t \sum Y}{n \sum Y t^{2}-\left(\sum t\right)^{2}}(\text { Pers 2.2) } \\
& a=\frac{n \sum Y-b \sum t}{n} \text { atau } \bar{Y}=b t
\end{aligned}
$$

Keterangan:

$\mathrm{n}=$ jumlah periode

$\mathrm{Y}=$ nilai dari deret waktu

Adapun cara kerja sistem MRP adalah sebagai berikut :

1. Menghitung waktu kebutuhan kotor dari persediaan yang diproyeksikan dan dijadwalakan penerimaan dari setiap material 
2. Mengkonversikan kebutuhan yang direncanakan dengan menggunakan ukuran lot.

3. Menerapkan rencana pemesanan pada periode yang tepat dengan menggunakan penjadwalan sebelumnya dari tanggal dibutuhkan dikurangi waktu siklus.

4. Menentukan tidakan-tindakan yang diperlukan bagi konsumen.

5. Ektrasi kebutuhan produk utama (porent) menjadi kebutuhan kotor setiap komponen yang berhubungan dengan BOM (Bill Of Material).

Metode EOQ sebenarnya bukan dimaksudkan untuk MRP. Sekalipun begitu, teknik ini dapat dengan mudah diterapkan pada MRP. Teknik ini didasarkan pada asumsi bahwa kebutuhan bersifat kontinu dengan pola permintaan yang stabil. Ukuran kuantitas pemesanannya (lot size) ditentukan dengan menggunakan rumus yaitu:

$$
\begin{array}{r}
\mathrm{S}=\frac{\sum_{\mathrm{i}-11}^{\mathrm{n}} \text { Kebutuhan Bersih }}{\mathrm{n}} \\
\mathrm{EOQ}=\sqrt{\frac{2 \mathrm{CS}}{\mathrm{H}}}
\end{array}
$$

Keterangan :

$\Sigma=$ Jumlah Keseluruhan

$\mathrm{C}=$ Ongkos Pesan

$\mathrm{H}=$ Ongkos Simpan

$\mathrm{S}=$ Rata-rata kebutuhan

$\mathrm{n}=$ Banyak Periode

\section{HASIL DAN PEMBAHASAN}

Pada langkah ini digali pemikiran teoritis yang kemudian di tuangkan dalam kebutuhan ril sistem yang telah di identifikasi pada Survei lapangan. Data Persediaan batu silika merupakan data yang memaparkan jumlah persediaan batu silika yang berolasikan di indarung II, Indarung III. Indarung IV dan Indarung V. Berikut ini merupakan tabel 1 data rekapitulasi persediaan batu silika bulan Januari 2019 sampai Oktober 2019.
Tabel 1. Data Rekapitukasi Persediaan Batu Silika Tahun 2019

\begin{tabular}{|c|l|c|c|c|c|}
\hline \multirow{2}{*}{ No } & \multirow{2}{*}{ Bulan } & \multicolumn{4}{|c|}{ Stock Batu Silika (Ton) } \\
\cline { 3 - 6 } & & Indarung II & Indarung III & Indarung IV & Indarung V \\
\hline 1 & JANUARI & 17850 & 27450 & 18700 & 213070 \\
\hline 2 & FEBRUARI & 15000 & 21750 & 15592,5 & 220025 \\
\hline 3 & MARET & 13500 & 23550 & 15075,5 & 236600 \\
\hline 4 & APRIL & 13500 & 16350 & 20218 & 207350 \\
\hline 5 & MEI & 13250 & 25800 & 18161 & 222625 \\
\hline 6 & JUNI & 13500 & 20100 & 17264,5 & 235300 \\
\hline 7 & JULI & 32450 & 28050 & 15658,5 & 242450 \\
\hline 8 & AGUSTUS & 21050 & 22050 & 19195 & 218335 \\
\hline 9 & SEPTEMBER & 21150 & 22950 & 18568 & 196950 \\
\hline 10 & OKTOBER & 15550 & 25950 & 20135,5 & 186875 \\
\hline & Jumlah & $\mathbf{1 7 6 8 0 0}$ & $\mathbf{2 3 4 0 0 0}$ & $\mathbf{1 7 8 5 6 8 , 5}$ & $\mathbf{2 1 7 9 5 8 0}$ \\
\hline
\end{tabular}

Untuk memproduksi semen dibutuhkan klinker yang telah ditambahkan dengan bahan lainnya seperti gypsum, pozzolan dan material ke-3. Namun proses pembentukan klinker sendiri memerlukan raw mix yang diperoleh dari campuran material seperti batu kapur, silika, tanah liat dan pasir besi. Berikut di bawah ini merupakan Bill Of Materials (BOM) dari produk semen.

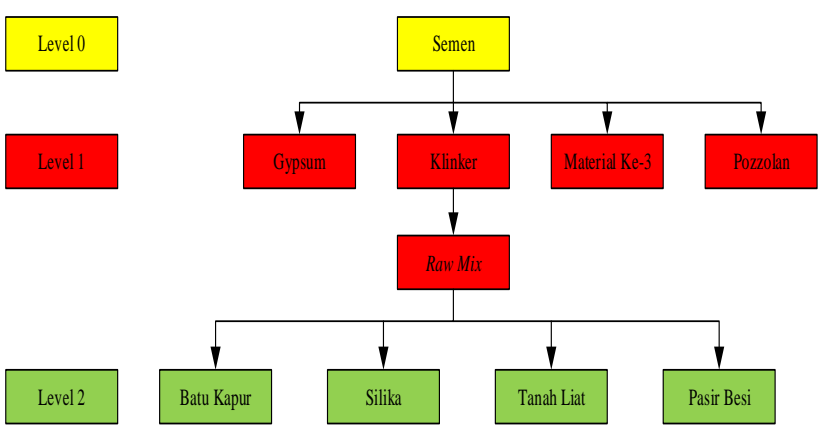

Gambar1 . Bill of Materials (BOM) Semen Padang

Dalam proses pengolahan data, penulis melakukan analisa pengendalian batu silika dengan menggunakan metode Material Requirement Planning (MRP) untuk mencapai tingkat persediaan yang optimal guna meminimalkan biaya persediaan.

Untuk biaya simpan merupakan biaya yang timbul akibat menyimpan batu silika. Biaya simpan diasumsikan tetap untuk jumlah kapasitas penyimpanan tertentu. Sedangkan biaya beli batu 
silika merupakan biaya yang dikeluarkan oleh perusahaan untuk memperoleh batu silika. Berikut di bawah ini merupakan biaya simpan dan biaya beli batu silika.

\section{Tabel 2. Biaya Simpan dan Biaya Beli} Batu Silika

\begin{tabular}{|l|l|}
\hline Keterangan Biaya & Harga \\
\hline Biaya Material & Rp1.400.000 \\
\hline Biaya Pesan Silika & Rp14.000 \\
\hline $\begin{array}{l}\text { Biaya Simpan } \\
\text { Silika }\end{array}$ & Rp2.800 \\
\hline
\end{tabular}

(Sumber, Bursa harga batu silika, 2019)

Untuk mengetahui kebutuhan batu silika pada bulan Januari 2019 hingga Oktober 2019 digunakan data persediaan batu silika pada bulan Januari 2018 hingga Otober 2019 dengan melakukan peramalan stock batu silika selama di tahun 2019 yang akan digunakan untuk menentukan persediaan batu silika pada tahun 2019 . Perhitungan peramalan metode exponensial dan metode linier yang terpilih untuk menetukan peramalan pada bulan Januari 2020 hingga Oktober 2020.

Perhitungan ini bermanfaat ketika ukuran variable ramalan bersifat penting saat mengevaluasi keakuratan pada ramalan. Perhitungan galat dilakukan terhadap ketiga metode peramalan untuk menentukan metode yang akan terpilih.

Tabel 3. Rekapitulasi Perhitungan Galat (MAPE)

\begin{tabular}{|c|l|c|c|}
\hline Wilayah & \multicolumn{3}{|c|}{ Indarung II } \\
\cline { 1 - 3 } No & \multicolumn{1}{|c|}{ Metode } & MAPE & Galat \\
\hline 1 & Linier & 0,214 & \multirow{2}{*}{201} \\
\hline 2 & Exponential & 0,201 & \\
\hline
\end{tabular}

\begin{tabular}{|c|l|r|c|}
\hline Wilayah & \multicolumn{3}{|c|}{ Indarung III } \\
\hline No & Metode & \multicolumn{1}{|c|}{ MAPE } & Galat \\
\hline 1 & Linier & 0,127 & \multirow{2}{*}{0,126} \\
\hline 2 & Exponential & 0,126 & \\
\hline
\end{tabular}

\begin{tabular}{|c|l|r|c|}
\hline Wilayah & \multicolumn{3}{|c|}{ Indarung IV } \\
\cline { 1 - 3 } No & \multicolumn{1}{|c|}{ Metode } & \multicolumn{1}{|c|}{ MAPE } & Galat \\
\hline 1 & Linier & 0,081 & \multirow{2}{*}{0,080} \\
\hline 2 & Exponential & 0,080 & \\
\hline Wilayah & \multicolumn{3}{|c|}{ Indarung V } \\
\hline No & Metode & MAPE & Galat \\
\hline 1 & Linier & 0,063 & \multirow{2}{*}{0,063} \\
\hline 2 & Exponential & 0,064 & \\
\hline
\end{tabular}

Tabel 4. Data Peramalan Batu Silika Wilayah Indarung II Metode Exponential

\begin{tabular}{|c|c|c|c|c|c|c|c|}
\hline No & $\begin{array}{c}\text { Periode } \\
(\mathrm{t})\end{array}$ & $\begin{array}{c}\text { Permintaan } \\
\text { (Ton) }\end{array}$ & $t^{*} y$ & $t^{2}$ & a & b & Peramalan (Ton) \\
\hline 1 & 1 & 17.850 & 17.850 & 1 & \multirow{10}{*}{13.773} & \multirow{10}{*}{710} & 14.484 \\
\hline 2 & 2 & 15.000 & 30.000 & 4 & & & 15.194 \\
\hline 3 & 3 & 13.500 & 40.500 & 9 & & & 15.904 \\
\hline 4 & 4 & 13.500 & 54.000 & 16 & & & 16.615 \\
\hline 5 & 5 & 13.250 & 66.250 & 25 & & & 17.325 \\
\hline 6 & 6 & 13.500 & 81.000 & 36 & & & 18.035 \\
\hline 7 & 7 & 32.450 & 227.150 & 49 & & & 18.745 \\
\hline 8 & 8 & 21.050 & 168.400 & 64 & & & 19.456 \\
\hline 9 & 9 & 21.150 & 190.350 & 81 & & & 20.166 \\
\hline 10 & 10 & 15.550 & 155.500 & 100 & & & 20.876 \\
\hline 55 & 55 & 176.800 & 1.031 .000 & 385 & & & 176.800 \\
\hline
\end{tabular}

Tabel 5. Data Peramalan Batu Silika Wilayah Indarung III Metode Exponential

\begin{tabular}{|c|c|c|c|c|c|c|c|c|c|}
\hline No & $\begin{array}{l}\text { Periode } \\
(\mathrm{t})\end{array}$ & $\begin{array}{l}\text { Permintaan } \\
\text { (Ton) }\end{array}$ & $t^{2}$ & $\ln y$ & $t * \ln y$ & $\ln a$ & a & b & $\begin{array}{l}\text { Peramalan } \\
\text { (Ton) }\end{array}$ \\
\hline 1 & 1 & 27.450 & 1 & 10,22 & 10,22 & \multirow{10}{*}{10,02} & \multirow{10}{*}{22.443} & \multirow{10}{*}{0,01} & 22.567 \\
\hline 2 & 2 & 21.750 & 4 & 9,99 & 19,97 & & & & 22.692 \\
\hline 3 & 3 & 23.550 & 9 & 10,07 & 30,20 & & & & 22.817 \\
\hline 4 & 4 & 16.350 & 16 & 9,70 & 38,81 & & & & 22.944 \\
\hline 5 & 5 & 25.800 & 25 & 10,16 & \begin{tabular}{|l|}
50,79 \\
\end{tabular} & & & & 23.071 \\
\hline 6 & 6 & 20.100 & 36 & 9,91 & 59,45 & & & & 23.198 \\
\hline 7 & 7 & 28.050 & 49 & 10,24 & 71,69 & & & & 23.327 \\
\hline 8 & 8 & 22.050 & 64 & 10,00 & 80,01 & & & & 23.456 \\
\hline 9 & 9 & 22.950 & 81 & 10,04 & 90,37 & & & & 23.586 \\
\hline 10 & 10 & 25.950 & 100 & 10,16 & 101,64 & & & & 23.716 \\
\hline Total & 55 & 234.000 & 385 & 100,491 & 553,15 & 10,02 & 22.443 & 0,01 & 231.373 \\
\hline
\end{tabular}


Tabel 6. Data Peramalan Batu Silika Wilayah Indarung IV Metode Exponential

\begin{tabular}{|c|c|c|c|c|c|c|c|c|c|}
\hline $\mathrm{N}_{0}$ & $\begin{array}{l}\text { Periode } \\
(\mathrm{t})\end{array}$ & $\begin{array}{c}\text { Permintaan } \\
\text { (Ton) }\end{array}$ & $t^{2}$ & $\ln y$ & t*lny & $\ln a$ & $\mathrm{a}$ & b & $\begin{array}{c}\text { Peramalan } \\
\text { (Ton) } \\
\end{array}$ \\
\hline 1 & 1 & 18.700 & 1 & 9,84 & 9,84 & \multirow{10}{*}{9,71} & \multirow{10}{*}{16.466} & \multirow{10}{*}{0,01} & 16.695 \\
\hline 2 & 2 & 15.593 & 4 & 9,65 & 19,31 & & & & 16.927 \\
\hline 3 & 3 & 15.076 & 9 & 9,62 & 28,86 & & & & 17.162 \\
\hline 4 & 4 & 20.218 & 16 & 9,91 & 39,66 & & & & 17.401 \\
\hline 5 & 5 & 18.161 & 25 & 9,81 & 49,04 & & & & 17.643 \\
\hline 6 & 6 & 17.265 & 36 & 9,76 & 58,54 & & & & 17.888 \\
\hline 7 & 7 & 15.659 & 49 & 9,66 & 67,61 & & & & 18.137 \\
\hline 8 & 8 & 19.195 & 64 & 9,86 & 78,90 & & & & 18.389 \\
\hline 9 & 9 & 18.568 & 81 & 9,83 & 88,46 & & & & 18.645 \\
\hline 10 & 10 & 20.136 & 100 & 9,91 & 99,10 & & & & 18.904 \\
\hline Total & 55 & 178.569 & 385,00 & 97,85 & 539,31 & 9,71 & 16.466 & 0,01 & 177.793 \\
\hline
\end{tabular}

Tabel 7. Data Peramalan Batu Silika Wilayah Indarung $\mathrm{V}$ Metode Linier

\begin{tabular}{|c|c|c|c|c|c|c|c|c|c|}
\hline No & $\begin{array}{l}\text { Periode } \\
\text { (t) }\end{array}$ & $\begin{array}{l}\text { Permintaan } \\
\text { (Ton) }\end{array}$ & $t^{2}$ & $\ln y$ & t"lny & In a & a & b & $\begin{array}{c}\text { Peramalan } \\
\text { (Ton) }\end{array}$ \\
\hline 1 & 1 & 213.070 & 1 & 12,27 & 12,27 & \multirow{10}{*}{12,35} & \multirow{10}{*}{230.992} & \multirow{10}{*}{$-0,01$} & 228.439 \\
\hline 2 & 2 & 220.025 & 4 & 12,30 & 24,60 & & & & 225.915 \\
\hline 3 & 3 & 236.600 & 9 & 12,37 & 37,12 & & & & 223.419 \\
\hline 4 & 4 & 207.350 & 16 & 12,24 & 48,97 & & & & 220.950 \\
\hline 5 & 5 & 222.625 & 25 & 12,31 & 61,57 & & & & 218.509 \\
\hline 6 & 6 & 235.300 & 36 & 12,37 & 74,21 & & & & 216.094 \\
\hline 7 & 7 & 242.450 & 49 & 12,40 & 86,79 & & & & 213.707 \\
\hline 8 & 8 & 218.335 & 64 & 12,29 & 98,35 & & & & 211.345 \\
\hline 9 & 9 & 196.950 & 81 & 12,19 & 109,72 & & & & 209.010 \\
\hline 10 & 10 & 186.875 & 100 & 12,14 & 121,38 & & & & 206.700 \\
\hline Total & 55 & 2.179 .580 & 385 & 122,89 & 674,98 & 12,35 & 230.992 & $\cdot 0,01$ & 2.174 .089 \\
\hline
\end{tabular}

Berikut ini merupakan perhitungan Economic Order Quantity untuk bahan baku batu silika pembuatan semen disetiap wilayahnya, yaitu:

1. Wilayah Indaruang II

$$
Q=\sqrt{\frac{2 \times 17.047 \times 14.000}{2.800}}=412,01 \text { ton }
$$

2. Wilayah Indaruang III

$$
Q=\sqrt{\frac{2 \times 23.137 \times 14.000}{2.800}}=481,88 \text { ton }
$$

3. Wilayah Indaruang IV

$$
Q=\sqrt{\frac{2 \times 17.779 \times 14.000}{2.800}}=421,65 \text { ton }
$$

4. Wilayah Indaruang V

$$
Q=\sqrt{\frac{2 \times 217.958 \times 14.000}{2.800}}=1476,34 \text { ton }
$$

Total Biaya $=$ Total Bahan X (Biaya Material + Biaya Pesan + (Biaya Simpan)

Biaya Simpan $=20 \%$ dari biaya pesan $=$ Rp. 2.800

$$
\begin{aligned}
= & 166.338 \text { Ton X (Rp. } \\
& 1.400 .000+\text { Rp. } 14.000+ \\
& \text { Rp. } 2.800) \\
= & 166.338 \text { Ton X Rp. } \\
& 1.416 .800 \\
= & \text { Rp. } 235.667 .214 .608
\end{aligned}
$$




\section{Tabel 8. Perhitungan MRP metode $E O Q$}

\begin{tabular}{|c|c|c|c|c|c|c|c|c|c|c|c|c|c|}
\hline \multirow{2}{*}{ Lokasi } & \multirow{2}{*}{ Keterangan } & \multicolumn{10}{|c|}{ Peramalan } & \multirow{2}{*}{$\begin{array}{l}\text { Total } \\
\text { Bahan } \\
\end{array}$} & \multirow{2}{*}{ Biaya Bahan Baku } \\
\hline & & 1 & 2 & 3 & 4 & 5 & 6 & 7 & 8 & 9 & 10 & & \\
\hline \multirow{3}{*}{ Indarung II } & NR & 14.380 & 14.916 & 15.472 & 16.048 & 16.646 & 17.266 & 17.909 & 18.576 & 19.268 & 19.986 & \multirow{3}{*}{166.338} & \multirow{3}{*}{ Rp235.667.214.608 } \\
\hline & Ukuran Lot & 412,88 & 412,88 & 412,88 & 412,88 & \begin{tabular}{|l|l|}
412,88 \\
\end{tabular} & 412,88 & 412,88 & 412,88 & 412,88 & 412,88 & & \\
\hline & Persediaan & 13.968 & 14.503 & 15.059 & 15.635 & 16.233 & 16.853 & 17.496 & 18.163 & 18.855 & 19.573 & & \\
\hline \multirow{3}{*}{ Indarng III } & $\mathrm{NR}$ & 22.567 & 22.692 & 22.817 & 22.944 & 23.071 & 23.198 & 23.327 & 23.456 & 23.586 & 23.716 & \multirow{3}{*}{226.563} & \multirow{3}{*}{ Rp320.994.771.409 } \\
\hline & Ukuran Lot & 481,01 & 481,01 & 481,01 & 481,01 & 481,01 & 481,01 & 481,01 & 481,01 & 481,01 & 481,01 & & \\
\hline & Persediaan & 22.086 & 22.211 & 22.336 & 22.463 & 22.590 & 22.717 & 22.846 & 22.975 & 23.105 & 23.235 & & \\
\hline \multirow{3}{*}{ Indarung IV } & NR & 16.695 & 16.927 & 17.162 & 17.401 & 17.643 & 17.888 & 18.137 & 18.389 & 18.645 & 18.904 & \multirow{3}{*}{173.576} & \multirow{3}{*}{ Rp245.922.927.357 } \\
\hline & Ukuran Lot & 421,65 & 421,65 & 421,65 & 421,65 & 421,65 & 421,65 & 421,65 & 421,65 & 421,65 & 421,65 & & \\
\hline & Persediaan & 16.273 & 16.505 & 16.741 & 16.979 & \begin{tabular}{|l|}
17.221 \\
\end{tabular} & 17.467 & 17.716 & 17.968 & 18.223 & 18.483 & & \\
\hline \multirow{3}{*}{ Indarung $\mathrm{V}$} & NR & 228.066 & 225.820 & 223.574 & 221.327 & 219.081 & 216.835 & 214.589 & 212.342 & 210.096 & 207.850 & \multirow{3}{*}{2.164 .817} & \multirow{3}{*}{ Rp3.067.112.157.899 } \\
\hline & Ukuran Lot & $1.476,34$ & $1.476,34$ & $1.476,34$ & $1.476,34$ & $1.476,34$ & $1.476,34$ & $1.476,34$ & $1.476,34$ & $1.476,34$ & $1.476,34$ & & \\
\hline & Persedian & 226.590 & 224.344 & 222.097 & 219.851 & 217.605 & 215359 & 213.112 & 210.866 & 208.620 & 206.374 & & \\
\hline
\end{tabular}

\section{KESIMPULAN}

Berdasarkan hasil analisa dan uraian hasil metode MRP pada persediaan bahan baku silika pada PT. Semen Padang, dapat diambil kesimpulan antara lain :

1. Metode yang terpilih untuk peramalan adalah untuk Indarung II MAPE yang terpilih metode exponential, untuk Indarung III MAPE yang terpilih metode

2. exonential, untuk Indarung IV MAPE yang terpilih metode exonential, dan untuk Indarung $\mathrm{V}$ MAPE yang terpilih metode linier.

3. Maka dapat diterapkan pada perusahaan untuk pengendalian peserdiaan bahan baku batu silika dengan menggunakan metode EOQ karna total biaya yang didapatkan lebih optimal untuk periode 10 bulan ke depan.

\section{DAFTAR PUSTAKA}

Arif, M., Supriyadi, S., \& Cahyadi (Universitas Serang Raya), D. (2017). Analisis Perencanaan Persediaan Batubara FX Dengan Metode Material Requirement Planning. Jurnal Manajemen Industri Dan Logistik, 1(2), 148. https://doi.org/10.30988/jmil.v1i 2.25
Assauri, S. (2016). Manajemen Operasi Produksi (Pencapaian Sasaran Organisasi Berkesinambungan) (3rd ed.). Jakarta: PT Raja Grafindo Persada.

Haming, M., \& Nurnajamuddin, M. (2017). Manajemen Produksi Modern Operasi Manufaktur Dan Jasa (2nd ed.). Jakarta: PT Bumi Aksara.

HANDOKO, T. H. (2012). Dasar-Dasar Manajemen Produksi Dan Operasi. Yogyakarta: BpfeYogyakarta.

Iksan. (2010). Perencanaan Dan Pengendalian Produksi Denganmenggunakan Metode Manufacturing Resources Planning Di Pt. Semen Gresik Tbk.

Irawan, P. A., \& Syaicu, A. (2017). Journal Knowledge Industrial Engineering (JKIE). Journal Knowledge Industrial Engineering, 4(1), 15-22. Retrievedfromhttp://jurnal.yudha rta.ac.id/v2/index.php/jkie/article /view/863/727

Ristono, A. (2013). Manajemen Persediaan. Yogyakarta: Ghara Ilmu.

Sofyan, D. K. (2013). Perencanaan \& Pengendalian PRODUKSI. Yogyakarta: Ghara Ilmu. 
Susetyo. (2017). Analisis Lot Sizing Least Unit Cost Untuk Efisiensi Biaya Persediaaan Resin Alkid Ag. Eko Susetyo, S.T., M.Sc. (Teknik Industri, Universitas Sarjanawiyata Tamansiswayogyakarta.). 55-66.

Teknik, F., Teknik, J., Universitas, S., Ratulangi, S., \& Walangitan. (2013). Manajemen Pengadaan Material Bangunan Dengan Menggunakan Metode Mrp ( Material Requirement Planning ) Studi Kasus: Revitalisasi Gedung Kantor Bps Propinsi Sulawesi Utara Inggried Limbong H . Tarore , J . Tjakra, $D$. R . O . Walangitan. Jurnal Sipil Statik, 1(6), 421-429. 